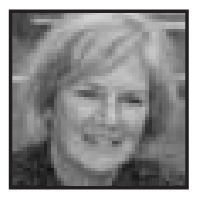

\title{
Art as "Connective Aesthetic": Creating Sites for Community Collaboration
}

\author{
Suzanne Thomas, University of Prince Edward Island
}

\section{ABSTRACT}

This paper discusses a community-based arts education project that develops partnerships between the university and cultural arts organizations. Collaboration is inspired between preservice teachers and multidisciplinary artists by engaging these two groups in the educational process. The author advocates the use of art as a heuristic tool for examining social worlds. She demonstrates how art as "connective aesthetic" creates sites for community collaboration and provides impetus for transformation and social change.

"Art offers life; it offers hope; it offers the prospect of discovery.... The arts offer opportunity for perspective, for perceiving alternative ways of transcending and of being in the world" (Greene, 1995, p. 133).

\section{Focus and Purpose}

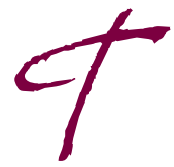

his article arises out of my work with Bachelor of Education students in a course entitled: Integrated Arts Inquiry at the Faculty of Education, University of Prince Edward Island. ' I facilitate opportunities for preservice teachers to explore creativity through a variety of artistic experiences and to expand their knowledge and expertise in critical inquiry. The framework of the course places emphasis on three primary areas of focus: exploration of the arts and issues of social advocacy, the transformative nature of the arts, and the use of art as a powerful tool for interrogating and disrupting social worlds. I encourage preservice teachers to experiment with a variety of art ideas, concepts, and approaches that may be 
integrated into teaching methodologies; to engage in experiential art making; and to develop critical perspectives in pedagogical practice. Preservice teachers are challenged to probe deeply and to interrogate critically dominant ideologies, and to envision inclusive, democratic spaces within their classrooms and communities.

Education in the arts is concerned with artistic processes that foster creativity, critical thinking, communication, and aesthetic appreciation. This course takes an integrative approach involving the visual and performing arts (dance, drama, music, visual art, creative writing); supports arts interdisciplinary curricular integration; and, fosters integration within local, community-based arts and culture organizations. Preservice teachers are encouraged to design inquiry projects that promote perspectives of diversity and critical thinking while establishing thriving networks within the arts community. My primary goal is to provide emerging teachers with fundamental strategies and approaches for applying arts integration in educational contexts. Specific objectives include demonstrating awareness of common elements in artistic and aesthetic experience; developing pedagogical approaches and instructional strategies related to integration of the arts; creating meaningful teaching/learning experiences in the arts that connect authentically to students' lives; gaining knowledge of local cultural institutions and community arts resources for curriculum enhancement; and building principles of inclusion and democracy through community partnerships.

\section{Conceptual Framework}

Theoretical perspectives and methodological traditions of place-based arts that foster recognition of place, local history, and culture, provide a conceptual framework (Blandy \& Hoffman, 1993; Bolin, 2000; Cohen-Cruz, 2002; deNobriga \& Schwarzman, 1999; Lai \& Ball, 2002). I embrace the notion of art as "connective aesthetic" (Gablik, 1995) as a perspective that affirms art as individual, social and cultural-inextricably linked with community and larger societal contexts. My course emphasizes art as a process of interrelatedness, interconnectedness, and social interaction as I enhance collaboration between emerging teachers and practicing artists by engaging these two groups in the educational process.

I consider the role of art as it relates to broad topics of education for diversity, equity, and social justice (Trifonas, 2005), and adopt "pedagogy of discomfort" as an educational approach to understanding the formation of norms and differences 
(Boler \& Zembylas, 2005, p. 111). I concur there is a need for both educators and students to move "outside comfort zones", to be willing to address contentious issues, and to examine ways we enact and embody dominant culture values and assumptions (Boler \& Zembylas, 2005, p. 111). I actively promote thinking critically about social justice issues, to consider perspectives of the dominant and privileged, the subordinate and marginalized, and to focus on expanding our collective capacity for engagement in "democratic dialogue" (Houston, 2005, pp. 106-107). My course emphasizes striving towards self-knowledge through a deepening awareness of social injustice, with the aim of uncovering invisible ways in which each of us perpetuate dominant ideologies.

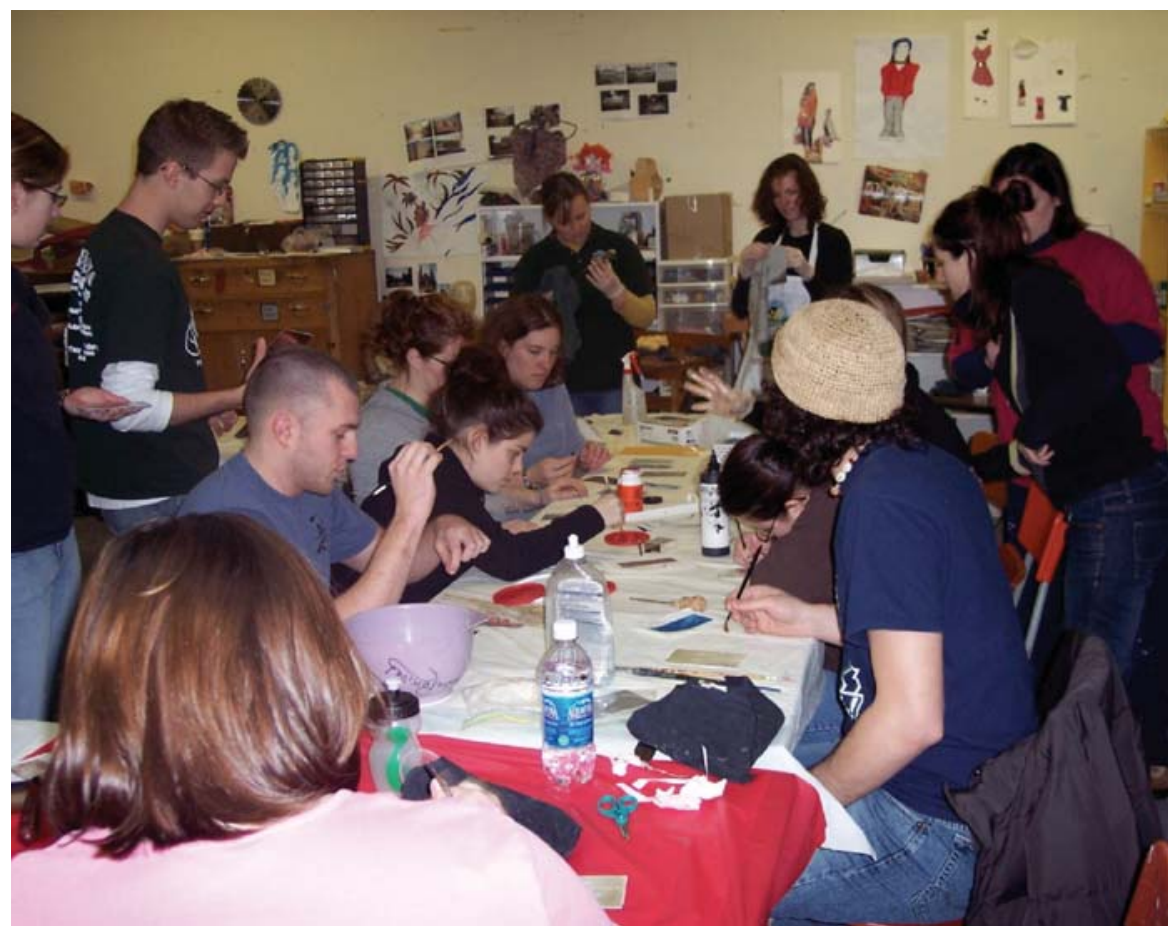

Fig. 1: In the artist-in-residence studio

The orientations of my course focus on concepts of art and social activism (Barndt, 2006; hooks, 1995) and "dialogue across difference" (Houston, 2005) as we examine the politics of place and the power dynamics of privileged positions. We collectively engage in critical discourse by interrogating "the normal" (Greene, 1995) to reconstruct visions of social worlds. Together, we examine our positions using a discursive approach to bring into consciousness place(s) and positions of self and other 
(Dixon \& Durrheim, 2000). We are guided by questions such as: How may art be used as a process for interrogating social justice issues and as a method for constructing and deconstructing meanings? How can the arts provide opportunities for the displacement of biases and stereotypes and create openings for re-constructing visions of social worlds? How might we envision arts integration in classroom practices to investigate dominant ideologies and to promote principles of inclusion and democracy? How might a focus on arts and social advocacy expand our ideas for critical pedagogical practice? What are our understandings of the potential for the arts to foster consciousness of multiple perspectives and to create impetus for social change?

\section{Creating a Context}

My primary objective is to develop partnerships between the university and local community-based arts organizations (Clark \& Zimmerman, 2000; Congdon, Blandy \& Bolin, 2001; Ulbricht, 2005). To this end, I situate learning within the context of community by establishing partnerships between Bachelor of Education students and members of the Charlottetown Festival Team, Dance Umbrella, and the Prince Edward Island Arts Council. I re-locate my Integrated Arts Inquiry course from a university classroom setting to the Confederation Centre for the Arts to promote community collaboration. The Confederation Centre for the Arts represents Canada's National Memorial to the Fathers of Confederation who gathered at Province House in 1864. The Centre stands on the site of the old Charlottetown marketplace and houses a Main Stage Theatre, Art Gallery, Artist-in-Residence Studio, Studio Theatre, and Dance Rehearsal Hall.

To broaden community networks, I introduce preservice teachers to local cultural arts institutions such as The Guild - a theatre and visual arts gallery highlighting regional island artist exhibitions and performances, and the Island Media Arts Co-operative-a media arts resource centre supporting work in video, film, and new media. These contexts provide alternate venues for artistic workshops and create opportunities to enhance community connectivity, to provide authentic art-making spaces, and to facilitate preservice teacher access and exposure to the vibrancy and richness of the arts world. 


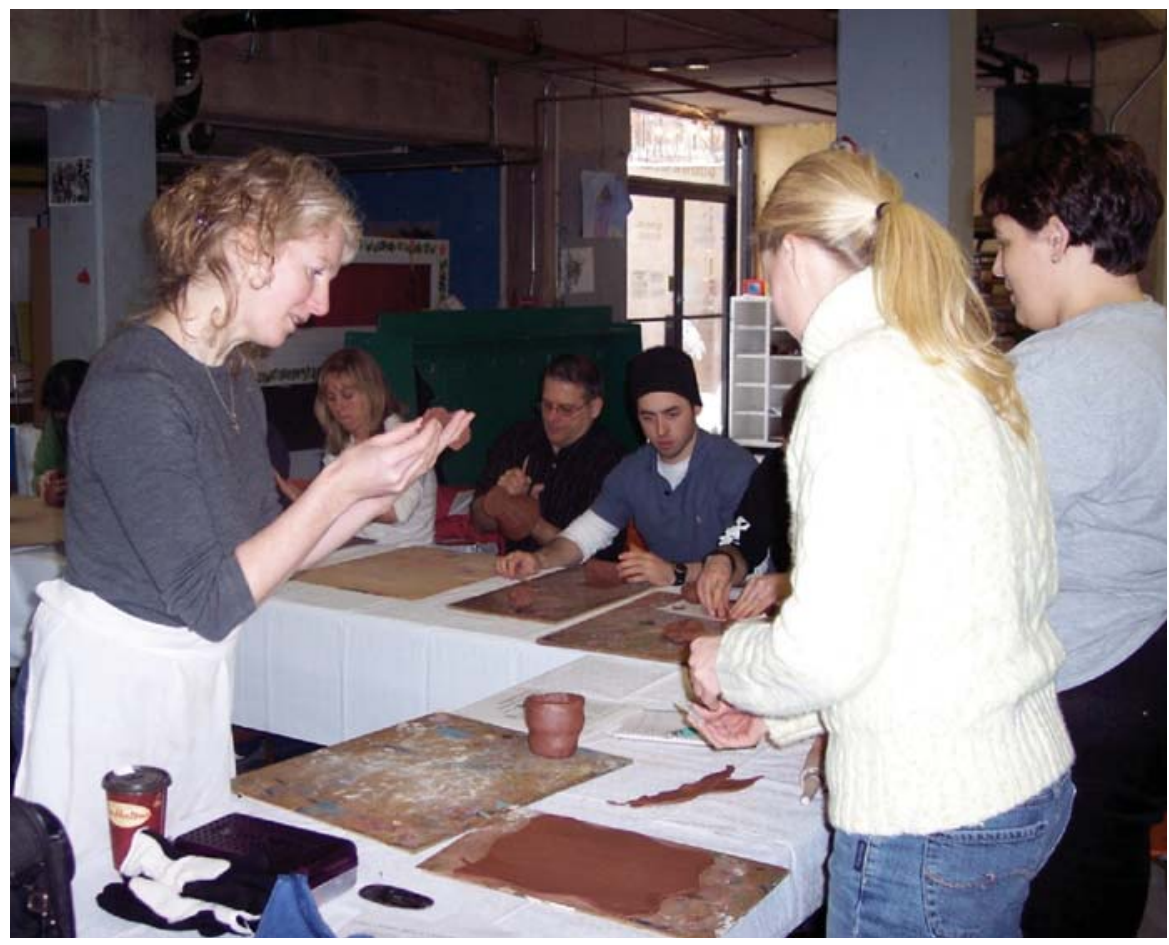

Fig. 2: Clay making with artist Sarah Saunders

\section{Modes of Integrated Arts Inquiry}

Through inquiry-based arts integration preservice teachers explore in-depth educational issues to promote student engagement in relevant, meaningful learning experiences. Preservice teachers collaboratively develop an integrated arts inquiry project comprised of three components. The first component involves identifying a key social issue; developing a conceptual framework by defining critical questions to be explored; providing a background rationale that identifies the relevance of the issue; and, outlining how the inquiry will promote critical perspectives. The second component includes designing a presentation format as performance or interactive exhibit; identifying at least three artistic modes to be applied in exploring the focus; listing materials and resources to be used to achieve interdisciplinary connections and enhance creative work; and, integrating theoretical perspectives to guide artistic elements, processes, and representational forms. As a culmination of the course, the final component focuses on synthesis and analysis of the inquiry process and includes audio/video documentation of preservice teachers' artistic productions. 
Creative works are performed live and simultaneously videotaped. Presentation responses include peer feedback critiques and post-performance dialogue with audience members.

I develop a process of integrated arts inquiry that consists of four fluid and interlinking phases: art making, art viewing, aesthetic interpretation, and critical discourse. In the art-making phase, practicing visual/performing artists guide preservice teachers in art studios, dance rehearsal hall, and theatre spaces. Art-making processes are documented in both still photographs and video as a form of "visual note-taking" (Müller, 2005). Preservice teachers are informed by their engagement with, and responses to, multi-disciplinary artists and their work. For example: Julia Sauvé, a member of Dance Umbrella, works with our class in the Mawson Rehearsal Hall to focus on dance/kinaesthetic movement. In her workshop, preservice teachers explore proprioception, the body's awareness of itself in space, and the essence of movement as time/space/energy. As one workshop participant describes:

The dance/movement class with Julia Sauvé was a wonderful experience. The class showed how movement gives kinaesthetic learners a way of expressing themselves, and was an excellent way to have people work collaboratively in groups to develop a creative performance piece on a particular topic. We also learned how to develop the concept of space, concentration, and coordination.

Local printmaker, Debra Percival, works with the class in the Confederation Centre Artist-in-Residence Studio. Her artwork "tells a story" as she creates inscriptions of imagery to render island place identity through photo intaglio printmaking. Debra guides preservice teachers in the techniques of printmaking "on and off" press. The following comments reflect a preservice teacher's response to the art-making session:

The printmaking experience with Debra was educational and fun. Using simple everyday materials such as ferns, wheat, lace, beads, rolling pins, paint and paper, we pressed them into beautiful works of art. This was a new technique that I discovered is simple enough to do with children of any age. The joy of it was that it was experimental and experiential in nature.

Wade Lynch, member of the Charlottetown Festival Team works with our class in the Mackenzie Theatre. He engages preservice teachers in an acting workshop that focuses on stage presence, character development and improvisation. Costumes and props add to character realization as preservice teachers deliver 
monologues following a series of role-playing exercises. The dramatic experience is illustrated in the words of a theatre participant:

Wade's workshop promoted our self-confidence and self-expression. He gave us many tips about auditioning, including some hilarious personal anecdotes, and showed us how to prepare for performance. It was risky for us to take a text, deconstruct it, and perform onstage "in character," in an attempt to make the role believable as a live encounter.

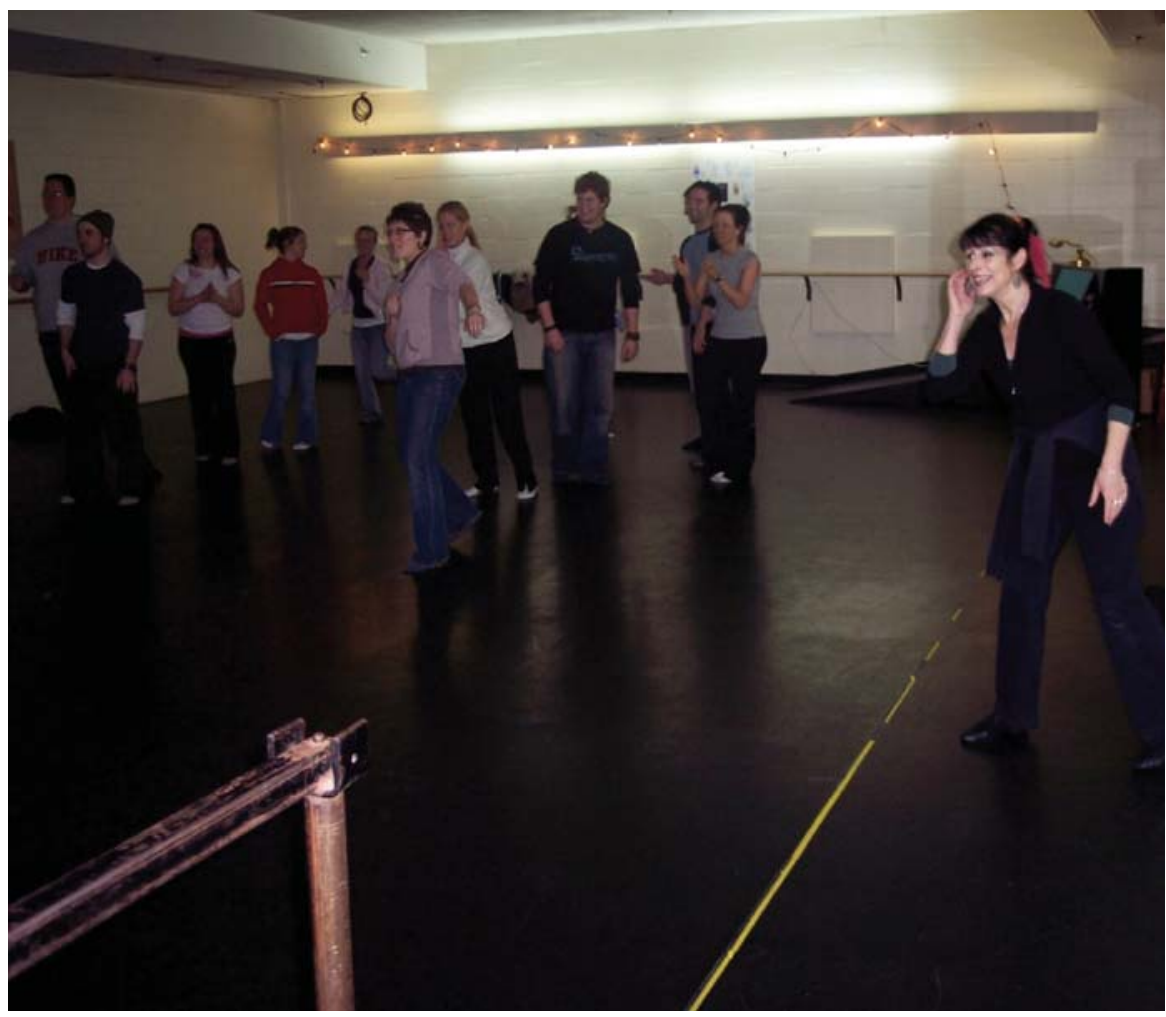

Fig. 3: In Mawson Rehearsal Hall with Julia Sauvé

\section{Art Viewing and Aesthetic Appreciation}

Preservice teachers' work is inspired by art viewing and conversations with local and visiting national artists. Emerging teachers engage in aesthetic interpretation by "looking behind the canvas" [and curtain] to see into the world of an artist 
(Winterson, 1995). Together we explore how aesthetic constructions of meaning reveal artists' beliefs, ideological assumptions, and social/cultural/political locations. To provide a few examples: the Prince Edward Island sculptor, Ahman Katz, creates a public forum to explore ways people select and identify symbols to represent place and memory. Working within a storefront studio, he uses archival photographs, cartography, and oral history to develop a series of clay models, New Monuments for Old Towns, as testimonies to people, place, and events that shape the community of Montague. The work of Ahman Katz inspires a visual art exhibit, Looking out... Looking In, consisting of sculptural forms created by preservice teachers to convey the complexity of inner and outer worlds and multiple perspectives of lived experience. Their sculptural installations depict representations of their unique identities, cultural heritage, and sense of place in community.

Saskatchewan artist, Ellen Moffat, works within a Charlottetown storefront studio to develop a mapping project entitled, Recall. Using satellite imagery of Prince Edward Island, colloquial expressions collected from local residents, and archival material, she explores the invisible residue that defines place. The artist illuminates hidden and forgotten elements of the island's local history by engaging community members such as marine biologists, fishermen, historians, artists, writers, and seniors in conversations to develop an inventory of significant, yet extinct items that define the island. Moffat's work represents place as a fleeting, illusory landscape in which specific historic events are remembered as reenactments. As a response to her artwork, preservice teachers present The Acadian Experience, a performance which explores origins of Acadian culture, identity, and language through conversational interviews with island residents. Teachers create onstage reenactments of Acadian cuisine, folklore, music and poetry, to represent invisible elements of the past stored in residual memory and oral culture. Their performance depicts an in-depth exploration of French language, identity, and history, pointing to issues of deportation, oppression of language, and culture.

In a photographic series, Cyborg Hybrids, Winnipeg artist, KC Adams, challenges mixed race classifications by using humorous text and imagery from two cultures. She refers to a "cyborg" as a creature in a technological, post-gender world free of traditional western stereotypes towards race and gender. In her Cyborg Hybrid series, KC Adams presents Euro-Aboriginal artists, wearing choker necklaces and T-shirts with beaded text such as "Authority on all Aboriginal Issues," "Indian Giver," and other slogans to illustrate common aboriginal racial stereotyping. She captures artists in stoic poses to mimic photos of aboriginal peoples from the $19^{\text {th }}$ and early $20^{\text {th }}$ centuries and alters imagery digitally to give them the appearance of models 
from a glamorous magazine. Artists' defiant poses challenge viewers to classify their identity. Living in the Shadows represents dramatic monologues informed by KC Adams' work in which preservice teachers demonstrate power relations embedded in language. They create a Shadow Theatre performance to reveal how racial and gender differences are constructed and re-create scenarios of discrimination observed in classrooms, playgrounds, and schools.

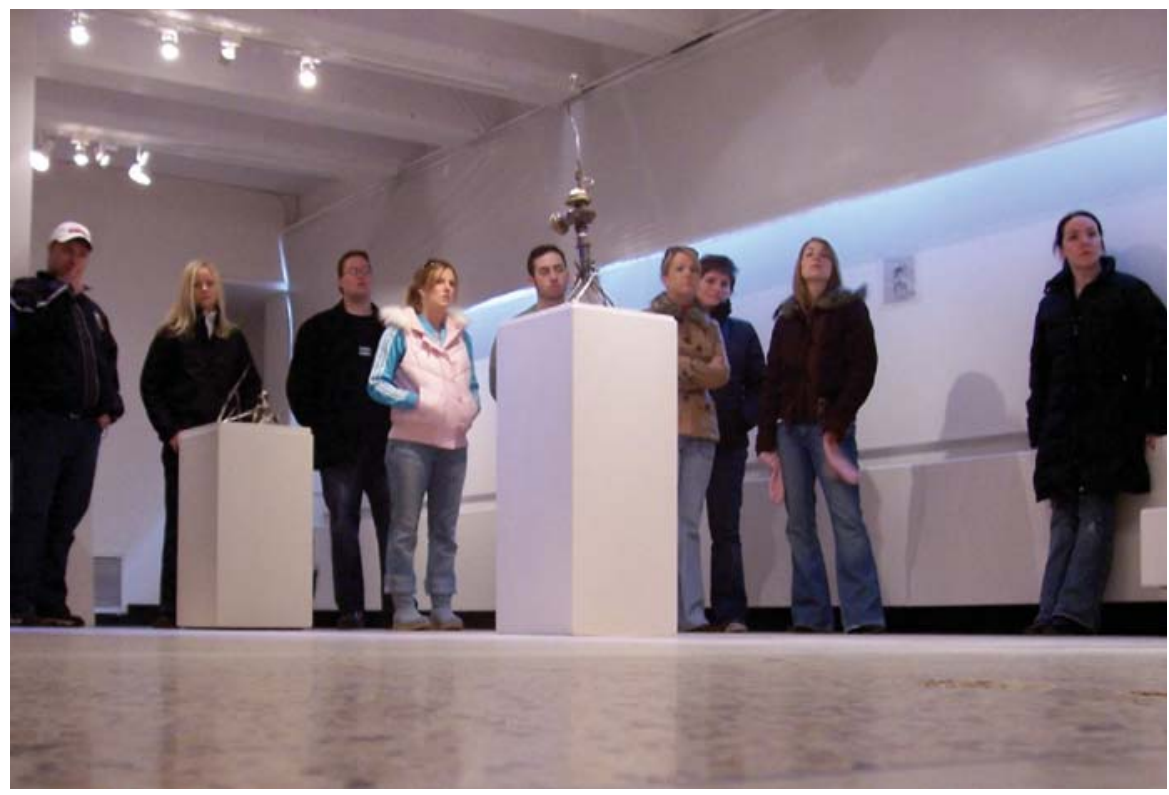

Fig. 4: Artist talk and viewing at the Guild Gallery

\section{Critical Discourse}

"Art opens space for critical thinking" (Cohen-Cruz, 2002, p. 8). In the final phase, emerging teachers engage in critical discourse to examine ideological underpinnings in their own work to uncover stereotypes and biases (Greene, 1995). Together we examine ways unequal experiences and differences are socially constructed and perpetuated by the educational system (Ng, 2003). "To engage in critical inquiry often means asking students [and teachers] to radically re-evaluate their worldviews" (Boler \& Zembylas, 2005, p. 111). In striving to achieve this, we consider questions such as: How does place become imbued with meaning? How are the notions of place defined by boundaries of language, ethnicity, race, gender, sexuality, and ablebodiness/disability? In the context of our classrooms: Whose place? Who 
belongs? Who becomes marginalized? In facilitating critical discourse, we reveal ideological assumptions, values and beliefs, while considering the role of art in "releasing the imagination" (Greene, 1995; 2001) and in opening possibilities for transformation and social change (Albers, 1999; Becker, 1994; Holloway \& Krensky, 2001).

Preservice teachers focus on issues related to gender, race, language, ethnicity, class, ablebodiness/disability, and sexual orientation. Integrated arts inquiries present a range of social issues such as HIV/Aids, local and global poverty, hunger, newcomers and immigration, emotional, physical and sexual abuse, bullying and the de-sensitization of youth, inclusion and ablebodiness, indigenous knowledges, homophobia, sexualization of young girls, the virtual environment, and social networking. We apply an approach to educational inquiry that addresses inequity and difference "to see difference as power relations that are produced in interactions" ( $\mathrm{Ng}$, 2003, p. 207). To provide a few examples: Bullying Inside Out, represents a performance in which teachers investigate emotional, physical, and psychological dimensions of bullying and explore the dynamics between the bully, bullied, and bystander. They create disturbing and provocative scenarios depicting racial, ethnic, religious and sexual discrimination through an interweaving of role-playing, song, and dance. Their presentation reveals multiple dimensions of bullying and its silent forms in cyber space. Hunger for Learning addresses issues of socioeconomic inequity through a moving and evocative performance of music, poetry, creative movement, and visual art. Preservice teachers illuminate the realities of hunger as a local and global phenomenon and reveal its often "hidden" and invisible dimensions. Their inquiry presents hunger as a complex social phenomenon and highlights its effects on the development of literacy and learning.

In Facebook, preservice teachers convey the impact of virtual reality on social relationships and networks. Their documentary film points out that as society continues its technological advancement relationships are more commonly established and maintained in a virtual format. Preservice teachers juxtapose historical concepts of social community based on diversity of values and beliefs, with a contemporary homogenization of community through development of networks based on similarities of interest. The film poses questions about changing notions of "friendship," social dynamics and social engagement, lack of face-to-face encounters, and the search for "multiple versions of self." 


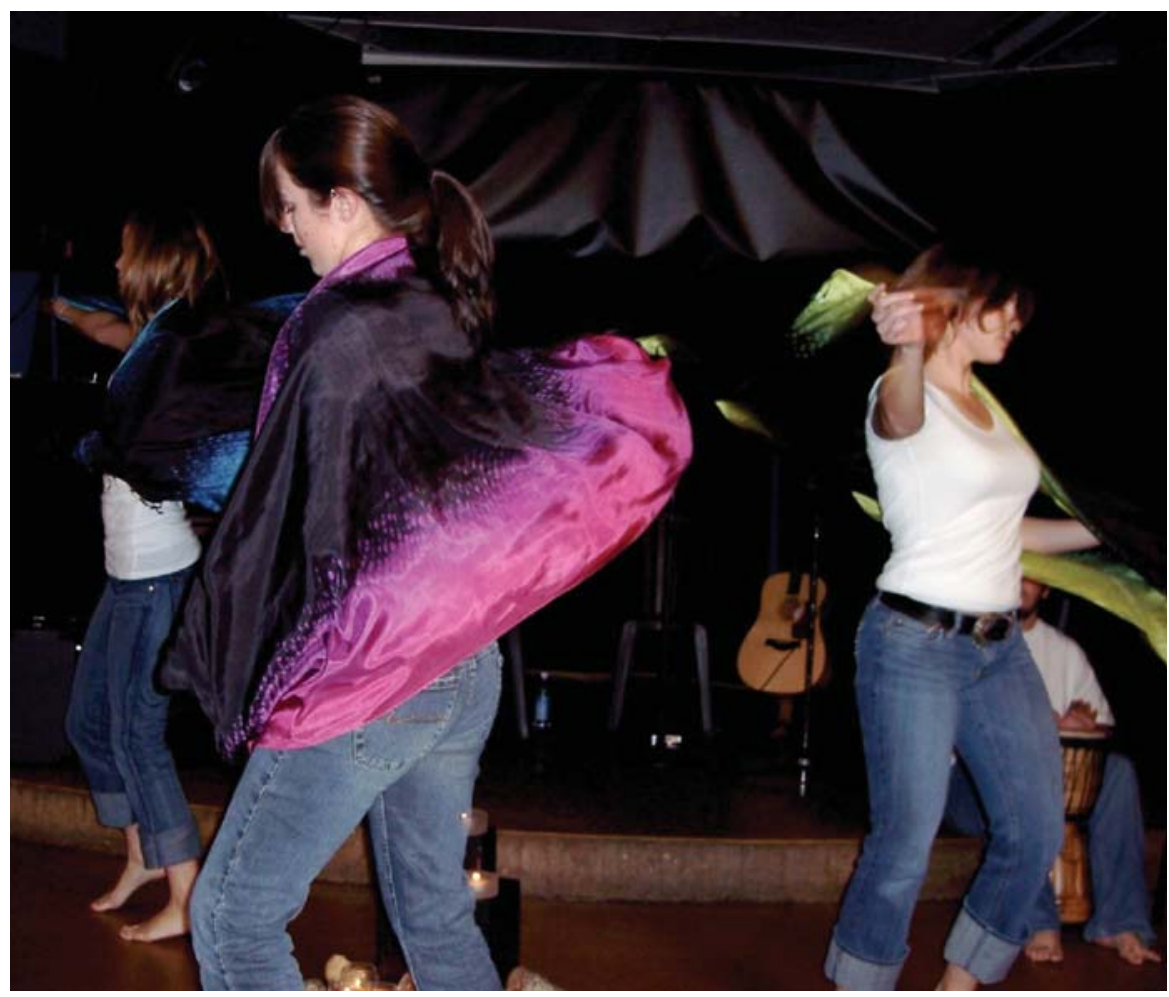

Fig. 5: Final performances at Mackenzie Theatre

\section{Examining Social Constructions}

Integrated arts inquiries depict interrogations of critical social issues and propel further questioning: How do prevailing social constructions influence discursive, pedagogical action? Collectively, as teachers and students, we confront our own embedded beliefs regarding gender, race, language, ethnicity, and underlying biases and stereotypes through our inter-subjective engagement with, and interpretation of, preservice teachers' work (Corbett, 2001; Yokley, 1999). The following text illustrates elements of the inquiry process as described by several members of one group:

Our integrated arts inquiry delved into issues pertaining to the evolution of identity among Aboriginal youth. We conducted interviews to explore Aboriginal identity from two distinct perspectives: the role within the Aboriginal community and the role within the dominant, Eurocentric society. We conducted interviews with a group of young Mi'kmaq adults and teachers by posing a 
leading question: "Do your feelings in the Aboriginal community differ from your feelings in the school context. If so, in what ways?" Interestingly, through our open-ended conversations, participants discussed distinctions between communities and their struggles between the two worlds.

We introduced the audience to several Mi'kmaq traditions and communicated issues that were raised throughout the interviews with a particular focus on the dual world phenomena, and the role of educators and schools in the development of positive Aboriginal identity in youth. Our performance created an opportunity for the audience to understand how racism and stereotyping can have a negative effect on minority groups such as Aboriginal youth. We feel our project will help diminish cultural biases in the classroom and hope it will encourage students and teachers to embrace difference. By raising awareness of the issues facing Aboriginal youth, we hope students and teachers will begin to take a critical look at how they might be promoting stereotypes and racism. Our documentary tells about real feelings and real situations that exist in school contexts with the hope of enlightening our class of future educators.

Coming Full Circle is a powerful, moving celebration of Aboriginal oral traditions and indigenous knowledge. It reveals how arts integration becomes a vehicle to give voice to marginalized cultures. The audience gains a glimpse into Mi'kmaq customs through a presentation of "smudging ceremony" prayers, singing, dancing, and traditional drumming, collaboratively presented by preservice teachers and Mi'kmaq members of the community. Their performance/presentation illuminates significant issues related to the formation of identity among Aboriginal youth, the presence of conflicting roles, and the inherent struggles and tensions existing between the duality of social worlds. Their work highlights multiple perspectives of identity development as seen through the lenses of Aboriginal youth workers, teachers, traditional drummers, and community workers. It points to the importance of curricular integration of Aboriginal perspectives and provokes deeper thinking about the educator's role and responsibility to interrogate issues of racism, to disrupt prevailing stereotypes, and to take action to "mend the circle" by fostering positive Aboriginal identity. The following comments reflect the group's synthesis of their inquiry experience:

As teachers we need to be reminded just how much power we have, and how that power is often abused because of ignorance. Teachers, who relate to their students, create equality in the classroom, and bring Aboriginal culture into the school, will help Aboriginal youth feel comfort with whom they are; who they are free to be in their communities. As educators, we need to allow our students 
to express themselves positively without any fear and teach our students to celebrate difference. Creating this presentation has been an "eye opening" experience for us. It has allowed us to immerse ourselves in the Aboriginal culture to learn more about it on a personal level. Without experiencing this, we might be like so many other teachers in the educational system who are scared to discuss this issue, or because it is so complicated, just not teach it at all.

Preservice teachers consider the potential for art to inform curriculum practice and to transform personal and professional worlds. Together, we probe the nature of our existing pedagogical practices by focusing on authority of voice, relations of power, and social influences. Tensions, conflicts, and contradictions are revealed in analysis of critical discourse leading each of us to think more inclusively and democratically, moving towards transformation. This process expands awareness of collective/cultural thinking, while challenging both teacher and class participants to interrogate social locations, and to create inclusive spaces within classrooms and communities. The following excerpts reveal thoughts, feelings, and perceptions of two course members:

After my group's performance I thought, "Wow, that was incredibly powerful! By working through the process, the problems, and our insecurities, we indeed integrated many forms of art without realizing the impact they could make together. Each of those elements alone would not have expressed the meaning we were trying to convey to our audience. Our message made a social statement; it had an impact. It embodied an important part of our teaching philosophy about promoting transformation, inclusion, and social change. It also allowed us to tap into our creativity; to express our unique personalities.

I really enjoyed the inquiry process of researching a social issue, developing our thoughts, feelings, and views on that topic, and combining our ideas as a group. To create an art performance that captures different aspects of that issue and perform it before an audience was both challenging and pleasurable. I don't think I realized the power of using art in this way. Our group performances really brought to light many vital, controversial, and necessary aspects of social injustice, forcing the audience to question social phenomena that are often overlooked. The performances were powerful, moving, and also chilling. After each performance, I felt the need to reflect on what I had viewed, and all that I was feeling. Sometimes it was fear, yet fear creates awareness and a sense of urgency needed to initiate social change. 


\section{Disseminating Knowledge}

Representations of integrated arts inquiries are disseminated through DVD documentation of creative productions for use as a future pedagogical tool. Creative works are also displayed in public places to provide a wider cultural sphere for further ideological debate and dialogue (Lund, 2005; Thomas \& Knowles, 2002). For example, a video ethnography produced by preservice teachers, Through Multiple Lenses: $A$ Critical Inquiry into Best Practice, was presented at a Research Forum to members of the educational community including students, teachers, administrators, Board Members, and post-secondary educators. In this work, preservice teachers probed notions of "best practice" through the lenses of faculty, experienced and emerging teachers, members of health organizations, and the business community. They focused on deconstructing the term "best practice" to uncover privileged positions by asking:Who defines "best practice"? Best for whom? By whom? Their documentary film represented multiple voices and perspectives, rupturing the notion of "best practice" by questioning whether it acts as a hegemonic tool or promotes critical inquiry and diversity. Preservice teachers problematized the concept of "best practice" within the educational field and examined how these notions related to wider teaching philosophies.

\section{Implications for Practice}

Emergent understandings generated from my course highlight four key factors: (1) the impact of engaging artists and teachers in the educational process. Creating spaces for collaboration between artists and preservice teachers stimulates critical thinking, informs emergent pedagogical practices, and affirms a multiplicity of perspectives. (2) Expansion of networks interconnecting links between teachers and cultural community organizations. Preservice teachers gain significant understanding of aesthetic values embedded in place-based arts, local history, cultural heritage, and communities. (3) The impact of place-based arts on teaching, curriculum, and pedagogy. Through the arts, teachers enact curricular events fostering connections with traditions and culture and engage students in reflexive examination of place both locally and globally, in larger societal contexts. (4) The impetus created for building principles of inclusion and democracy through community partnerships. Emerging teachers are challenged to probe deeply and critically; to create inclusive, democratic spaces within their classrooms and communities. Integrated arts initiatives promote social 
integration while advancing the potential role of the arts to awaken critical consciousness and to re-envision social/cultural worlds.

At the end of the course preservice teachers are asked to consider how their integrated arts inquiry has transformed pedagogical orientations, attitudes, beliefs, and has informed the evolution of their teaching philosophy. New insights are poignantly revealed in the voices of four individual course participants:

I was not really sure what to expect when we started this class. I was excited because I am interested in the arts, but I was concerned that the final project was going to be a waste of time. When the instructor emphasized to us that the inquiry project was more about process than product, I was sceptical. We are a group that is strongly focused on product and I wasn't sure how easy it would be to completely switch our mind frame. However, I discovered that the process was really exciting. The night before our performance I realized just how important the process had been. We felt liberated; we felt powerful; we felt as if we had a moment in this program when we could break out of the mould that has confined us.

I think art can be used to teach about issues that relate to social awareness and responsibility. Art education can help students become engaged citizens and empower them to take ownership of and become active participants in social change. Art can be a meaningful way to give voice to students, to help them explore their thoughts and feelings, the feelings of others, and to critique themselves and society. I think that integrating the arts can motivate students and help them recognize what is distinctive and unique about their own individuality, and that of others.

I believe in designing highly participatory lessons that support experiential learning, promote community connections, and nurture social responsibility and global citizenship. I believe it is important to use strategies that engage students in inquiry, problem solving, and decision-making situations. These types of investigations help encourage critical thinking and give meaning and relevance to the content. I believe that the arts can be used as means to interpret the world by making meaningful applications and connections. Art can connect the school to communities and make connections across subjects. Community connections help nurture relationships, allow students to recognize diverse views, and encourage students to develop positive attitudes about themselves and others. 
I am not going to say this course was easy, because it was not. Our inquiry showed me that I can succeed in areas outside my own personal comfort zone, and my success has fuelled a desire to continue this work. By taking me out of my comfort zone, the course has instilled within me a new sense of confidence. The emphasis placed on "process" over "product" allowed each of us to take risks. I see the value of presenting similar opportunities in my own classroom environment. I see great potential for my students to take ownership of a project to explore a social issue and to enhance the learning of their own peers. I think integrated arts inquiry fosters the ability in our students to become more actively involved citizens in today's society.

As an educator, I advocate the use of art as a powerful tool to open spaces for critical aesthetic perspectives and to provide impetus for continued personal/professional growth and transformation. I develop inquiry-based art education practices that foster tolerance, respect, diversity and empathy, to collectively build democratic community thereby making art more socially responsive (Rosler, 1994). I believe "it is the responsibility of the teacher or educator to show how dominant forms of knowledge and ways of knowing constrict human capacities" (Ng, 2005, p. 215). As Kinchloe (in Steinberg, 2006) suggests, knowledge is "created when teachers and students confront a contradiction," when teacher or student-presented information collides with experience (p. 147). I engage with my students to generate new meanings and shared interpretations as we move towards expanded consciousness of social problems of injustice. We are hopeful that in those spaces of "spaces of discomfort" we will discover new ways of perceiving and being in the world. Through retrospective and forward-gazing glances, our hope is to continue to collide and shift perspectives, to transform our worldviews to embrace values of social agency, efficacy, and affirmation of difference. Art as connective aesthetic breaks down social/cultural boundaries, enabling educational institutions working together with cultural arts organizations to become effective critical sites of community building and social cohesion. 


\section{Notes}

1. The author gratefully acknowledges the contributions of second-year preservice teachers in the Bachelor of Education Integrated Arts Inquiry courses at the University of Prince Edward Island. Permission was granted by preservice teachers and participating artists to reference their work and to include supporting photographs for educational purposes.

\section{References}

Albers, P. M. (1999). Art education and the possibility of social change? Art Education, $52(4), 7-11$.

Barndt, D. (Ed.). (2006). Wild fire: Art as activism. Toronto, Ontario: Sumach Press.

Becker, C. (Ed.). (1994). The subversive imagination: Artists, society, and social responsibility. New York, NY \& London, UK: Routledge.

Blandy, B., \& Hoffman, E. (1993). Toward an art education of place. Studies in Art Education, 35(1), 22-33.

Boler, M. \& Zembylas, M. (2005). Discomforting truths: The emotional terrain of understanding difference. In P. P. Trifonas (Ed.), Communities of difference: Culture, language, technology (pp. 110-136). New York, NY: Palgrave Macmillan.

Bolin, P. (2000). The value of local history and place within art education. Art Education, 53(4), 4-5.

Clark, G., \& Zimmerman, E. (2000). Greater understanding of the local community: A community-based art education program for rural schools. Art Education, 5(2), 29-33.

Cohen-Cruz, J. (2002). An introduction to community art and activism. Community Arts Network Reading Room. Retrieved June 30, 2005, from http://www.communityarts. net/readingroom/archivefiles/2002. html

Congdon, K. G., Blandy, D., \& Bolin, P. E. (Eds.). (2001). Histories of community-based art education. Reston, VA: National Art Education Association.
Corbett, M. (2001). Against the tide of modernity: Poststructuralism, rural schooling, place and resistance. In A. Butler, L. Clegham et al. (Eds.), Transforms: Insurgent voices in education (pp. 24-59). Toronto, Ontario: The Ontario Institute for Studies in Education, University of Toronto.

deNobriga, K., \& Schwarzman, M. (1999). Community-based art for social change. Community Arts Network Reading Room. Retrieved June 30, 2005, from http:// www.communityarts.net/readingroom/ar chivefiles/1999. html

Dixon, J., \& Durrheim, K. (2000). Displacing placeidentity: A discursive approach to locating self and other. British Journal of Social Psychology, 39, 27-44.

Gablik, S. (1995). Connective aesthetics: Art after individualism. In S. Lacy (Ed.), Mapping the terrain: New genre public art (pp. 74-87). Seattle, WA: Bay Press.

Greene, M. (1995). Releasing the imagination: Essays on education, the arts, and social change. San Francisco, CA: Jossey-Bass.

Greene, M. (2001). Variations on a blue guitar: The Lincoln Center Institute lecture on aesthetic education. New York, NY \& London, UK: Teacher's College Press.

Holloway, D., \& Krensky, B. (2001). The arts, urban education and social change. Education \& Urban Society, 33(4), 354-365.

hooks, b. (1995). Art on my mind: Visual politics. New York, NY: The Vintage Press. 
hooks, b. (2003). Teaching community: A pedagogy of hope. New York, NY: Routledge.

Houston, B. (2005). Democratic dialogue: Who takes responsibility? In $\mathrm{M}$. Boler (Ed.), Democratic dialogue in education: Troubling speech, disturbing silence (pp. 105-120). New York, NY: Peter Lang.

Lai, A., \& Ball, E. L. (2002). Home is where the art is: Exploring places people live through art education. Studies in Art Education: A Journal of Issues and Research, 44(1),47-66.

Lund, D. E. (2005). Tackling difference in the conservative heartland of Canada. In P. P. Trifonas (Ed.), Communities of difference: Culture, language, technology (pp. 27-35). New York, NY: Palgrave Macmillan.

Müller, M. (2005). The memo book: Films, videos, and installations by Matthias Müller. Toronto: Ontario: YYZ Books.

$\mathrm{Ng}$, R. (2005). Toward an integrative approach to equity in education. In P. P. Trifonas (Ed.), Communities of difference: Culture, language, technology (pp. 206-219). New York, NY: Palgrave Macmillan.
Rosler, M. (1994). Place, position, power, politics. In C. Becker (Ed.), The subversive imagination: Artists, society and social responsibility (pp. 55-76). New York, NY: Routledge.

Steinberg, S. (2006). Critical multiculturalism and democratic schooling. In P. McLaren (Ed.), Rage and hope: Interviews with Peter McLaren on war, imperialism and critical pedagogy (pp. 139-167). New York, NY: Peter Lang.

Thomas, S., \& Knowles, J. G. (2002). Through the camera lens: Students focused on place in schools. Journal of Critical Inquiry into Curriculum and Instruction, 4(3), 7-14.

Trifonas, P. P. (Ed.). (2005). Communities of difference: Culture, language, technology. New York, NY: Palgrave Macmillan.

Ulbricht, J. (2005). What is community-based art education? Art Education, 58(2), 6-12.

Winterson, J. (1995). Art objects: Essays on ecstasy and effrontery. New York, NY: Vintage International.

Yokley, S. H. (1999). Embracing a critical pedagogy in art education. Art Education, 52(5), 18-24.

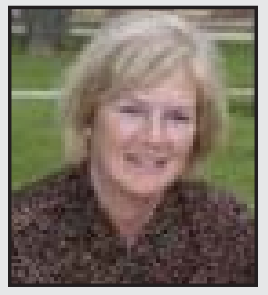

Suzanne Thomas is an Assistant Professor in the Faculty of Education at the University of Prince Edward Island. She is author of earth and flesh and bones and breath: Landscapes of Embodiment and Moments of Re-enactment (2004) and has published journal articles, book chapters, and multimedia publications in areas of arts education and social justice, island studies, and arts-informed research methodology. Her research interests focus on nissopoesis as poetic inquiry, visual inquiry, and cultural/aesthetic constructions of islands. She is currently Co-ordinator of the Masters of Arts, Island Studies Program, at the University of Prince Edward Island. 